\title{
Effect of Magnesium Content on Resonance Fatigue Life of Aluminum - Magnesium Alloy FSW Weld
}

\author{
Na Yang and Zhian Shi \\ Mechanical and electrical technology department, Xijing University, Shanxi Xi'an, China \\ 515569778@qq.com
}

\begin{abstract}
Keywords: Friction stir welding; Vibration fatigue life; Magnesium content; Crack propagation; Slip zone
\end{abstract}

\begin{abstract}
Friction stir welding (FSW) was conducted on three kinds of Al-Mg alloy of different magnesium content. Vibration fatigue life under resonant frequency was obtained according to the test standard of plane bending fatigue testing of metal plates. The crack propagation characteristic of the sample was observed with microscope and the influence of the magnesium content on resonant fatigue life of the FSW sample was also analyzed. Researches show that the resonant fatigue life of the sample with low magnesium content (about $0.44 \mathrm{wt} \%$ ) increases after FSW, which increases from $0.9 \times 105$ to $4.1 \times 105$. The slip band of the FSW sample generated during FSW is beneficial to the reduction of the crack propagating driving force, thereby increasing the vibration fatigue life of the specimen. The crack propagation of high magnesium content $(4.32 \mathrm{wt} \%)$ sample is a mixed-mode of transgranular and intergranular, which is one of the causes lead to the decrease of vibration fatigue life.
\end{abstract}

\section{Introduction}

Aluminum and aluminum alloy has a low density, good mechanical properties, processing performance, thermal conductivity, conductivity and corrosion resistance. Aluminum and aluminum alloys are increasingly used in the field of ships and marine equipment. Aluminum and aluminum alloy to reduce the hull structure quality, improve the speed and resistance to seawater corrosion, reduce energy consumption has an important role ${ }^{[1]}$.

FSW is a solid-state connection technology invented by the British Welding Institute. Because it avoids the traditional melting welding defects, especially suitable for welding magnesium and aluminum and other non-ferrous metals. FSW is widely used in aerospace and land transportation tools and other fields. However, the initial invention of the FSW has been extended to date, which is mainly used in hull welding.

Due to the special working environment, the hull structure has been subject to cyclic changes in the load, resulting in failure to form the main form of fatigue. At present, in China developed aluminum alloy hulls mostly use welding structure. Design units and manufacturing plants need to understand the fatigue life of the welded joints of the main force parts of the hull, the characteristics of the fatigue failure and the impact of the welding process and defects on these properties ${ }^{[2]}$.Friction stir welding of 3 kinds of $\mathrm{mg} \mathrm{Al}$ $\mathrm{Mg}$ alloy was carried out, and the effect of magnesium content on the resonance fatigue life of friction stir welds was studied.

\section{Test Method}

Experimental materials are three kinds of different magnesium that are $0.44 \mathrm{wt} \%, 2.56 \mathrm{wt} \%$ and 4.32wt\%.The A44 samples, A256 samples and A432 samples were used respectively, Chemical composition of raw material is shown by Tab.1.All samples were annealed before the experiment, in which the A44 sample was annealed for 415 hours under the condition of heat preservation for 2 hours; The A256 and A432 samples were cooled for 350 hours at room temperature for 2 hours. The A44, 
A256 and A432 samples after friction stir processing were represented by A44-FSW, A256-FSW and A432-FSW respectively.

Table.1 Chemical composition of raw material (wt\%)

\begin{tabular}{ccccccc}
\hline & $\mathrm{Mg}$ & $\mathrm{Fe}$ & $\mathrm{Cr}$ & $\mathrm{Si}$ & $\mathrm{Mn}$ & $\mathrm{Al}$ \\
\hline $\mathrm{A} 44$ & 0.44 & 0.19 & 0.001 & 0.39 & 0.03 & allowance \\
$\mathrm{A} 256$ & 2.56 & 0.26 & 0.21 & 0.15 & 0.10 & allowance \\
$\mathrm{A} 432$ & 4.32 & 0.18 & 0.10 & 0.07 & 0.89 & allowance \\
\hline
\end{tabular}

The test system is composed of computer, ultrasonic generator, excitation power, piezoelectric transducer, displacement amplifier, sample clamp, pull rod, displacement sensor and amplifier.

The specimen is fixed on the clamp rod, the ultrasonic generator controlled by computer from low frequency to high frequency vibration, record the sample maximum offset frequency is the resonance frequency of the sample. The sample size of the three kinds of magnesium is the same as that of the vibration fatigue sample, and its structure is shown in Fig.1. The thickness of the sample is $3.5 \mathrm{~mm}$. The fatigue life of each sample was measured 3 times, and the values were recorded respectively in order to draw the curve of fatigue life.

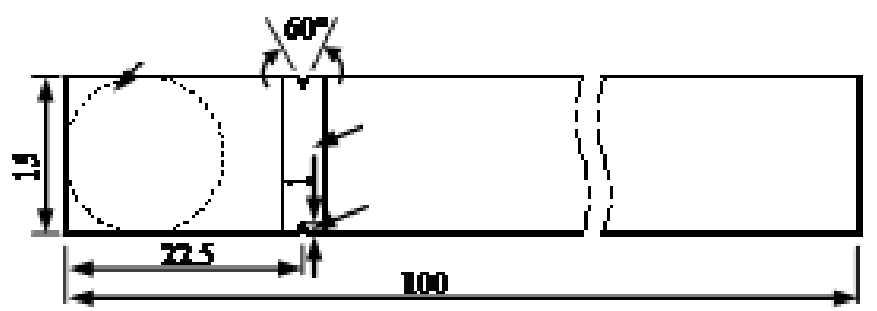

Figure 1. Schematic diagram of the vibration fatigue sample

\section{Test Result}

The Vibration Fatigue Life. The resonant frequency of the A44 sample and its FSW sample is the same, which is about $41-1 \mathrm{~Hz}$, and the resonance frequencies of A256 and A432 samples and FSW samples are the same, about $36+1 \mathrm{~Hz}$.

The vibration fatigue tests were carried out at the resonant frequencies of the samples, and the vibration offset curves of the samples showed a trend of increasing first and then decreasing, which is shown by Fig. 2 From the starting point to the peak of the curve is called the first stage. From the peak of the curve to the end of the curve is called the second stage. According to the previous studies [5], It can be seen from the figure that the vibration suppression performance of the sample after the same offset is different. The difference of the vibration suppression performance of the first stage is different the resonance life of the sample is defined as the number of vibration cycles corresponding to the first stage, which is called the vibration fatigue life of the specimen.

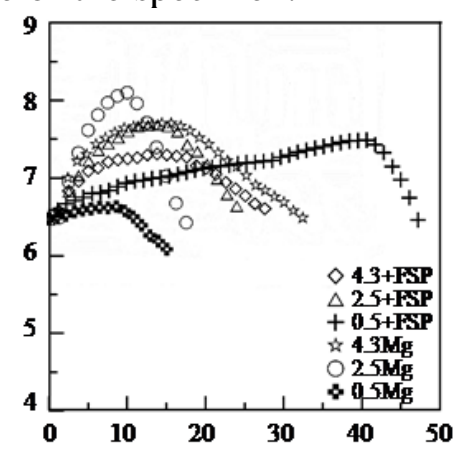

Figure 2. Vibration offset - cycle curves 
The vibration fatigue life of the sample - the magnesium content curve is shown in Fig. 3. It can be seen that the vibration fatigue life of FSW samples decreases with the increase of the content of magnesium, but the vibration fatigue life of the specimens without stirring mother increases with the increase of the content of magnesium alloy, but the increase is not obvious. After the friction stir processing, the vibration fatigue life of A44 samples was increased from $0.9 * 105$ to $4.1 * 105$, and the vibration fatigue life of other samples was not obvious.

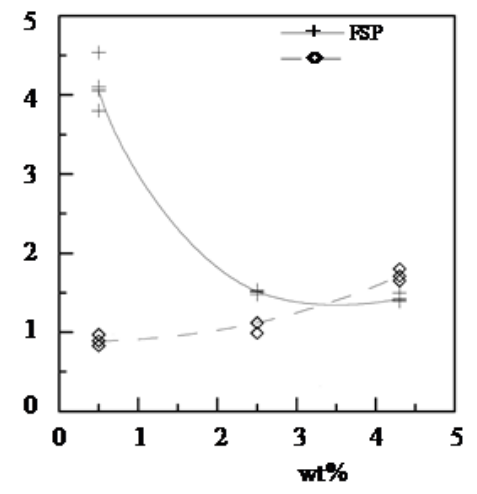

Figure 3. Vibration fatigue life - magnesium content curves

Specimen Crack Microstructure, Fig. 4 shows the sample microstructure of friction stir cracks. The smaller the magnesium content is the more the slip zone along the crack, and the influence of the magnesium content on the crack propagation mechanism. It is pointed out in the literature [6] that a large number of slip bands absorb vibration energy and improve the fatigue life of the specimens.
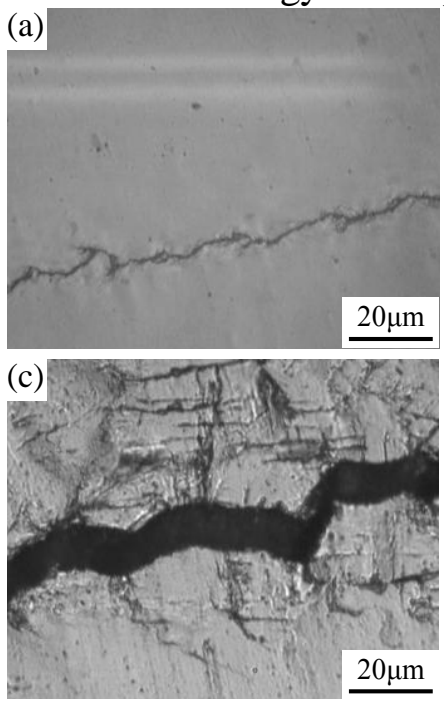

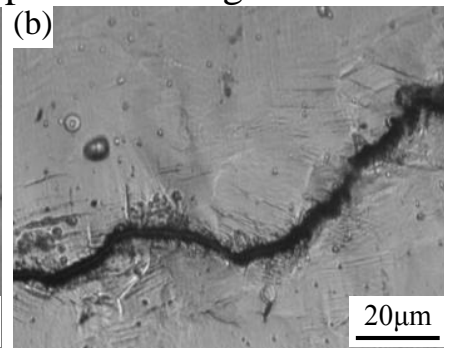

(a) A44-FSW; (b) A256-FSW;

(c) A432-FSW

Figure 4. Microstructure of the crack in vibration fatigue sample

The crack propagation path of high magnesium content (4.32wt\%) is shown in Fig.5. A432 base metal crack propagation mode is transgranular propagation. However, when the content of magnesium is higher than that of A432-FSW, the crack propagation path is straight and some of them are along the grain boundary. 

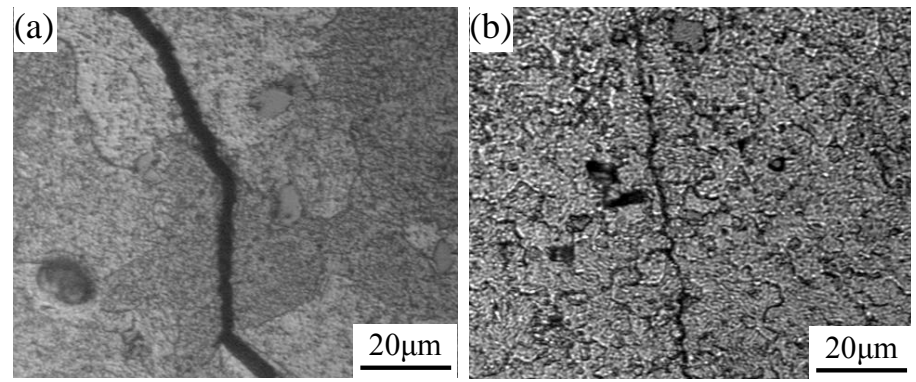

Figure 5. Microstructure of the crack in corroded sample

\section{Summary}

The vibration fatigue life of the specimens was significantly decreased with the increase of $\mathrm{Mg}$ content.

The smaller the content of magnesium in the friction stir sample is, the more the slip zone of the crack is, the sliding zone produced by the vibration of the friction specimen can effectively reduce the driving force of the crack propagation, thus improving the vibration fatigue life of the specimen.

The propagation of crack propagation in the friction stir specimens with higher $\mathrm{Mg}$ content is a mode of transgranular and intergranular propagation, which is one of the reasons for the low fatigue life.

\section{References}

[1] Liu Yanxi. Research Progress on corrosion protection of aluminum alloy[J]. Modern Paint and Finishing, 2007, 10(12): 11-14.

[2] Li Piaofeng, Li Jingyong. Study on fatigue properties of aluminum magnesium alloy welded joints [J]. Ship Science and Technology, 1995, 17(05):44-55.

[3] JIS Z 2275. Method of plane bending fatigue testing of metal plates [S]. Japanese Industrial Standard /Japanese Standards Association, 1978.

[4] Jiang D S, Chen L H, Truan-Sheng L. Effect of Aging on the Crack Propagation Behavior of A356 Alloy under Resonant Vibration [J]. Materials Transactions Jim, 2000, 41(4):499-506.

[5] Ramaraju K, Prasad Y V R K, Vasu K I. Slip structure and crack growth during fatigue in aluminum and aluminum-1\% magnesium [J]. Metallography, 1972, 5(3):265-273.

[6] Baker S P. Plastic deformation and strength of materials in small dimensions [J]. Materials Science \& Engineering A, 2001, 319(244):16-23.

[7] Prasad K E, Rajesh K, Ramamurty U. Micropillar and macropillar compression responses of magnesium single crystals oriented for single slip or extension twinning [J]. Acta Materialia, 2014, 65(6):316-325. 